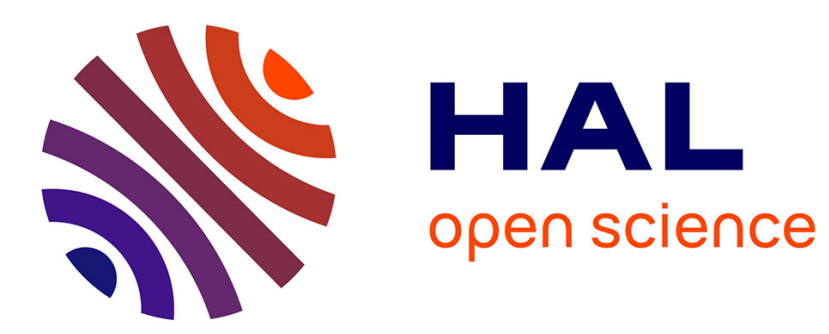

\title{
Network mechanisms of spindle-burst oscillations in the neonatal rat barrel cortex in vivo.
}

\author{
Marat Minlebaev, Yehezkel Ben-Ari, Rustem Khazipov
}

\section{To cite this version:}

Marat Minlebaev, Yehezkel Ben-Ari, Rustem Khazipov. Network mechanisms of spindle-burst oscillations in the neonatal rat barrel cortex in vivo.. Journal of Neurophysiology, 2007, 97 (1), pp.692-700. 10.1152/jn.00759.2006 . inserm-00483860

\section{HAL Id: inserm-00483860 https://www.hal.inserm.fr/inserm-00483860}

Submitted on 17 May 2010

HAL is a multi-disciplinary open access archive for the deposit and dissemination of scientific research documents, whether they are published or not. The documents may come from teaching and research institutions in France or abroad, or from public or private research centers.
L'archive ouverte pluridisciplinaire HAL, est destinée au dépôt et à la diffusion de documents scientifiques de niveau recherche, publiés ou non, émanant des établissements d'enseignement et de recherche français ou étrangers, des laboratoires publics ou privés. 


\section{Network Mechanisms of Spindle-Burst Oscillations in the Neonatal Rat Barrel Cortex In Vivo \\ Marat Minlebaev, Yehezkel Ben-Ari and Rustem Khazipov \\ J Neurophysiol 97:692-700, 2007. First published Nov 8, 2006; doi:10.1152/jn.00759.2006}

You might find this additional information useful...

This article cites 68 articles, 34 of which you can access free at:

http://jn.physiology.org/cgi/content/full/97/1/692\#BIBL

Updated information and services including high-resolution figures, can be found at:

http://jn.physiology.org/cgi/content/full/97/1/692

Additional material and information about Journal of Neurophysiology can be found at: http://www.the-aps.org/publications/jn

This information is current as of February 6, 2007 . 


\title{
Network Mechanisms of Spindle-Burst Oscillations in the Neonatal Rat Barrel Cortex In Vivo
}

\author{
Marat Minlebaev, Yehezkel Ben-Ari, and Rustem Khazipov \\ The Mediterranean Institute of Neurobiology, Institut National de la Santé et de la Recherche Médicale U29, Université Méditerrenéen, \\ Marseille, France
}

Submitted 21 July 2006; accepted in final form 6 November 2006

\begin{abstract}
Minlebaev M, Ben-Ari Y, Khazipov R. Network mechanisms of spindle-burst oscillations in the neonatal rat barrel cortex in vivo. $J$ Neurophysiol 97: 692-700, 2007. First published November 8, 2006; doi:10.1152/jn.00759.2006. Early in development, cortical networks generate particular patterns of activity that participate in cortical development. The dominant pattern of electrical activity in the neonatal rat neocortex in vivo is a spatially confined spindle-burst. Here, we studied network mechanisms of generation of spindle-bursts in the barrel cortex of neonatal rats using a superfused cortex preparation in vivo. Both spontaneous and sensory-evoked spindle-bursts were present in the superfused barrel cortex. Pharmacological analysis revealed that spindle-bursts are driven by glutamatergic synapses with a major contribution of AMPA/kainate receptors, but slight participation of NMDA receptors and gap junctions. Although GABAergic synapses contributed minimally to the pacing the rhythm of spindleburst oscillations, surround GABAergic inhibition appeared to be crucial for their compartmentalization. We propose that local spindleburst oscillations, driven by glutamatergic synapses and spatially confined by GABAergic synapses, contribute to the development of barrel cortex during the critical period of developmental plasticity.
\end{abstract}

\section{N T R O D U C T I O N}

During development, cortical neuronal networks generate particular patterns of activity that participate in cortical development (Ben-Ari 2001; Fox 2002; Katz and Shatz 1996; Khazipov and Luhmann 2006; Moody and Bosma 2005; O'Donovan 1999). The dominant pattern of electrical activity in the neonatal rat neocortex in vivo is a spindle-burst (Hanganu et al. 2006; Khazipov et al. 2004b). Spindle-bursts are spatially confined spindle-shape oscillations at alpha-beta frequency, associated with phase-locked neuronal firing and activation of the glutamatergic and GABAergic synapses. Spindle-bursts constitute a self-organizing pattern that persists after deafferentation. In the intact animal, compartmentalized spindle-bursts in somatosensory cortex are triggered by sensory feedback resulting from spontaneous movements in a somatotopic manner (Khazipov et al. 2004b). In visual cortex, spindle-bursts are triggered by spontaneous retinal waves in an eye-specific manner (Hanganu et al. 2006). However, the network mechanisms underlying the generation of cortical spindle-bursts are poorly understood. Several patterns of correlated neuronal activity sharing some common features with the spindle-bursts in vivo were previously described in postnatal rodent neocortical and hippocampal slices and intact preparations in vitro. These include "synchronized-via-gapjunctions neuronal domains" (Kandler and Katz 1995 1998a,b; Yuste et al. 1992, 1995) and calcium waves (Peinado 2000,

Address for reprint requests and other correspondence: R. Khazipov, INMED/INSERM U29,163 Avenue de Luminy, B.P. 13, 13273 Marseille, France (E-mail khazipov@inmed.univ-mrs.fr).
2001), gap-junction- and NMDA-receptor-based cholinergic oscillations (Dupont et al. 2006), giant depolarizing potentials (GDPs), and early network oscillations driven by glutamatergic and excitatory GABAergic synapses (Agmon et al. 1996; Ben-Ari et al. 1989; Garaschuk et al. 1998, 2000; Khazipov et al. 1997; Leinekugel et al. 1997, 1998). Consistent with the in vitro findings, generation of the early hippocampal in vivo pattern of sharp waves (Buhl and Buzsáki 2005; Leinekugel et al. 2002) was also shown to involve excitatory action of $\gamma$-aminobutyric acid (GABA) (Sipilä et al. 2006). However, to what extent these developmentally regulated mechanisms contribute to generation of the neocortical in vivo pattern of spindle-bursts remains largely unknown.

In the present study, we studied the mechanisms of spindlebursts in the neonatal rat barrel cortex in vivo using a superfused neocortex preparation initially developed for the adolescent rat hippocampus (Khazipov and Holmes 2003). We found that the physiological pattern of spindle-bursts is preserved in the superfused barrel cortex. Pharmacological profiling of spindle-bursts indicated that 1 ) generation of spindle-bursts is primarily based on glutamatergic synapses, with a major role of $\alpha$-amino-3-hydroxy-5-methyl-4-isoxazolepropionic acid (AMPA) receptors and a slight contribution of $N$-methyl-Daspartate (NMDA) receptors and gap junctions; and that 2) GABAergic synapses are not directly involved in the generation of spindle-burst oscillations, although they play an important role in their spatial compartmentalization.

\section{METHODS}

This study followed INSERM guidelines on animal care, with approval from the animal care and use local committee. Wistar rats of both sexes from postnatal day (P) 1 to P7 were used. P0 was the day of birth. During the surgical procedure, rats were anesthetized with a combination of $0.5-1.5 \mathrm{~g} / \mathrm{kg}$ urethane injected intraperitoneally and ice-cooling. The skin and periosteum were removed from the skull, which was then covered with a layer of dental acrylic, except for two areas about $7 \mathrm{~mm}$ in diameter above the right and left barrel cortices (Fig. 1A). The rat was positioned in the stereotaxic apparatus; the skull was attached to the nose (nasal bones) and ear bars (occipital bone) with dental acrylic. A 5-mm-diameter burr hole was drilled in the skull above the right barrel cortex, the dura was cut and removed, and the cortical surface was covered with $0.9 \% \mathrm{NaCl}$ during the procedure to prevent it from drying. The perfusion chamber was prepared as described previously (Khazipov and Holmes 2003) with some modifications. In brief, a 2-mm-long cylinder was cut from a plastic tube (ID $3.5 \mathrm{~mm}$, OD $4.5 \mathrm{~mm}$ ) and glued to stretched nylon mesh with cyanoacrylamide glue. The chamber was positioned at the cortical

\footnotetext{
The costs of publication of this article were defrayed in part by the payment of page charges. The article must therefore be hereby marked "advertisement" in accordance with 18 U.S.C. Section 1734 solely to indicate this fact.
} 
A

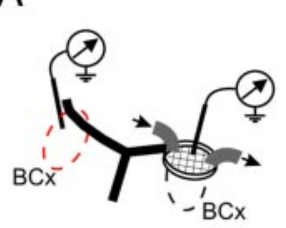

B
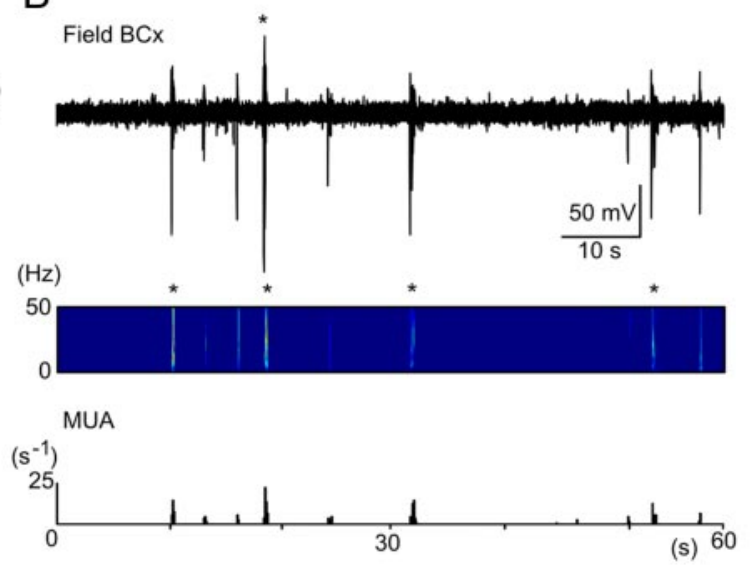

C
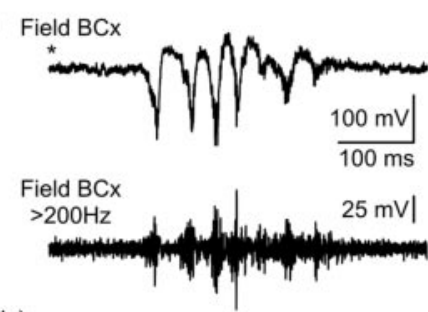

$(\mathrm{Hz})$

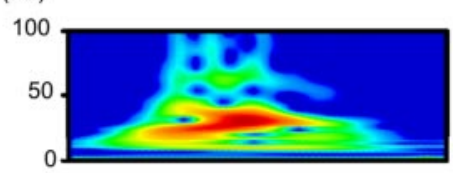

$\mathrm{F}$

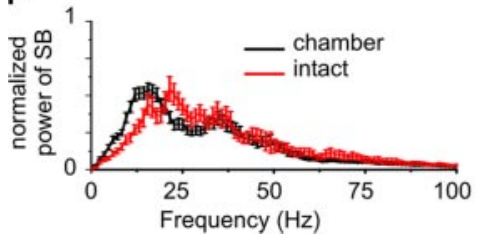

D Field $\mathrm{BCx}$
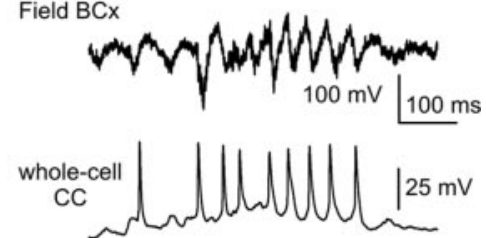

$\mathrm{E}$

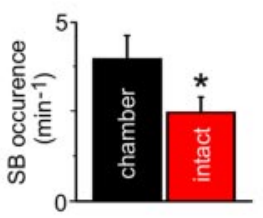

G

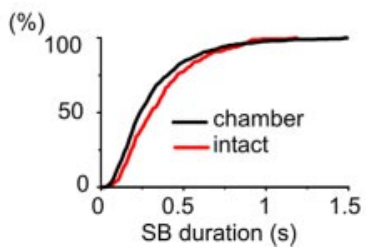

FIG. 1. Spindle-bursts in the superfused barrel cortex of neonatal rat in vivo. $A$ : scheme (top) and photograph (bottom) of the experimental preparation. Perfusion chamber is a cylinder with fine mesh at its bottom. It is placed at the surface of barrel cortex so that mesh gently presses on the cortex to prevent pulsations. This construction allows application of drugs directly on the cortical surface. Pair of stimulation electrodes is implanted into the whisker pads. $B$ : local field potential recordings (3- to 3,000-Hz band-pass) from the postnatal day $4(\mathrm{P} 4)$ rat superfused barrel cortex $(\mathrm{BCx})$; below are shown the corresponding time-frequency analysis and multiple unit activity (MUA). Spindle-bursts are marked with asterisks. $C$ : spindle-burst marked by asterisk on $B$ (top trace) is shown on an expanded timescale. $D$ : action potentials of individual cortical neuron recorded concomitantly in current-clamp mode during the spindle-burst oscillation (depth, $600 \mu \mathrm{m}) . E-G$ : spindle-burst occurrence $(E)$, duration $(G)$, and normalized power $(F)$ in the superfused and intact barrel cortices. Pooled data from 13 P2-P7 rats; total 1,165 spindle-bursts. surface so that the mesh gently pressed onto the cortex. The chamber was then fixed to the skull by dental acrylic. Chlorided silver wire was inserted into the cerebellum and served as a ground electrode.

During recordings, rats were heated by a thermal pad $\left(37^{\circ} \mathrm{C}\right)$. The chamber was perfused with oxygenated $\left(95 \% \mathrm{O}_{2}-5 \% \mathrm{CO}_{2}\right)$ artificial cerebrospinal fluid (ACSF) of the following composition (in $\mathrm{mM}$ ): $126 \mathrm{NaCl}, 3.5 \mathrm{KCl}, 2.0 \mathrm{CaCl}_{2}, 1.3 \mathrm{MgCl}_{2}, 25 \mathrm{NaHCO}_{3}, 1.2 \mathrm{NaH}_{2} \mathrm{PO}_{4}$, and 11 glucose ( $\mathrm{pH} 7.4$ at a rate of $2 \mathrm{ml} / \mathrm{min}$ ). Temperature in the chamber was kept at $35-37^{\circ} \mathrm{C}$ using an automatic temperature controller (TC-344B; Warner Instruments, Hamden, CT). Extracellular field potential recordings $(\times 1,000 ; 3$ - to $3,000-\mathrm{Hz}$ band-pass $)$ were performed using arrays of metal electrodes of $50 \mu \mathrm{m}$ in diameter (California Fine Wire, Grover Beach, CA). Patch-clamp recordings were performed using a Axopatch 200A amplifier (Axon Instruments, Union City, CA) using a patching technique similar to that described in vivo (Leinekugel et al. 2002; Margrie et al. 2002). The pipettes were filled with a solution of the following composition (in mM): 135 Cs-gluconate (or methylsulfate), $2 \mathrm{MgCl}_{2}, 0.1 \mathrm{CaCl}_{2}, 1 \mathrm{EGTA}$, and 10 HEPES ( $\mathrm{pH}$ 7.25). Membrane potential values were corrected for liquid junction potential of $+12 \mathrm{mV}$. Afferent stimulation was performed by applying electrical pulses $\left(60 \mathrm{~V}, 50 \mu \mathrm{s}, 0.03 \mathrm{~s}^{-1}\right)$ through pairs of electrodes inserted into the whisker pads and glued to the skin with super glue.

Data were digitized at $10 \mathrm{kHz}$ using a Digidata $1322 \mathrm{~A}$ interface (Axon Instruments) and analyzed off-line using an Axon package
(Axon Instruments), MiniAnalysis (Synaptosoft, Decatur, GA), Origin (Microcal Software, Northampton, MA), and Matlab (The MathWorks, Natick, MA). Group measures are expressed as means $\pm \mathrm{SE}$. The statistical significance of differences was assessed with the Student's $t$-test. The level of significance was set at $P<0.05$.

The drugs gabazine, 6-cyano-7-nitroquinoxaline-2,3-dione (CNQX) and D-2-amino-5-phosphonovaleric acid (D-APV) were purchased from Tocris Neuramin (Bristol, UK), diazepam from Roche (Basel, Switzerland), and all other compounds from Sigma (St. Louis, $\mathrm{MO})$.

\section{RES U L T S}

To study the mechanisms of spindle-bursts in the barrel cortex of neonatal rats (postnatal days P1-P7), we used a technique of superfused neocortex in vivo that was originally developed for adult hippocampus (Khazipov and Holmes 2003). The photograph and the experimental setup are schematically shown in Fig. $1 A$. In brief, under anesthesia, a round window was cut in the scull above the barrel cortex and dura was removed. A cylinder with fine mesh at its bottom was gently pressed onto the surface of the barrel cortex (mesh prevents pulsations and allows application of drugs directly onto the cortical surface). In addition to the ease of pharma- 
cological manipulations, this technique is also convenient for placement of electrodes. The contralateral barrel cortex remained intact and served as a control.

We first determined whether the normal physiological pattern of spindle-bursts and sensory-evoked responses are preserved in the superfused barrel cortex by comparing the activity in the barrel cortex superfused with normal ACSF with the intact contralateral barrel cortex using local field potential recordings (3- to 3,000-Hz band-pass). Spontaneous activity in both superfused and intact barrel cortices was similar and characterized by highly discontinuous periods of activity. Virtually all multiple unit activity (Fig. 1, $B$ and $C$ ) and action potentials of individual cortical neurons recorded concomitantly in current-clamp mode $(n=9$ cells; Fig. $1 D)$ were synchronized to intermittent spindle-shape oscillations. These were similar to the spindle-bursts described previously in the primary somatosensory cortex for areas of body representation (Khazipov et al. 2004b) as well as in visual cortex (Hanganu et al. 2006). Spindle-bursts had similar durations of $344 \pm 15$ and $370 \pm 15 \mathrm{~ms}$ and peak power of oscillations at $15 \pm 3$ and $21 \pm 3 \mathrm{~Hz}$, and reversed in polarity at about $1 \mathrm{~mm}$ depth (in the superfused and intact barrel cortices) (Fig. $1, F$ and $G ; n=13$ rats; P2-P7). Spindle-bursts occurred more frequently in the superfused barrel cortex $\left(4.2 \pm 0.4 \mathrm{~min}^{-1}\right)$ than in the intact barrel cortex $\left(2.5 \pm 0.4 \mathrm{~min}^{-1} ; P<0.05\right.$; Fig. $\left.1 E\right)$.

Sensory potentials evoked by electrical stimulation of the contralateral whisker pad occurred with a similar delay of $38.3 \pm 1.4$ and $39.5 \pm 3.5 \mathrm{~ms}$ and had amplitudes of $792 \pm 49$ and $593 \pm 12 \mu \mathrm{V}$ in the superfused and intact barrel cortices, respectively (Fig. $2 A ; n=17$ rats; P2-P7). Relatively long latencies of sensory responses are typical for the immature animals and human and they probably reflect the lack of myelinization (Khazipov et al. 2004b; Pihko and Lauronen 2004). Transcortical current source density analysis of the sensory-evoked potentials (100- $\mu \mathrm{m}$-depth increment) in the superfused barrel cortex revealed a major sink in the middle cortical layers (Fig. $2 B ; n=3$ rats; P4). Whole cell recordings with a low-chloride pipette solution were used to discriminate between glutamatergic and GABAergic events. At the reversal potential of the $\mathrm{GABA}_{\mathrm{A}}$-mediated postsynaptic currents (PSCs, around $-60 \mathrm{mV}$ ) and glutamatergic excitatory (E)PSCs (around $0 \mathrm{mV}$ ), sensory stimulation sequentially evoked EPSCs and GABA-PSCs (Fig. $2 C ; n=5$ neurons, depth from 450 to $600 \mu \mathrm{m})$. Sensory-evoked EPSCs coincided with the field potential response (delay, $44.1 \pm 1.9 \mathrm{~ms}$ ), whereas the sensory-evoked GABAergic component was organized in a barrage of GABA-PSCs similar to the responses evoked by stimulation in the neonatal thalamocortical slices (Agmon et al. 1996). First, GABA-PSCs in a barrage occurred $9.8 \pm 1.6 \mathrm{~ms}$
A
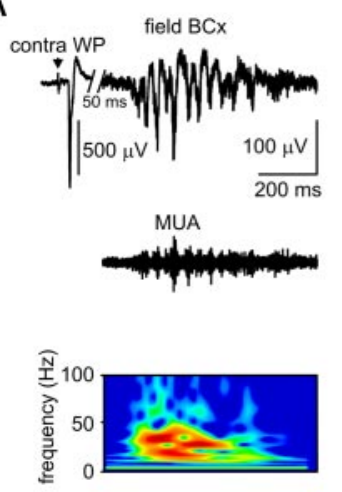

B

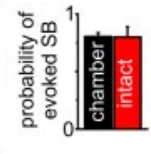

C

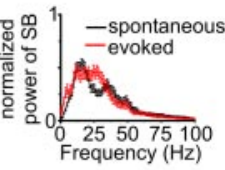

D

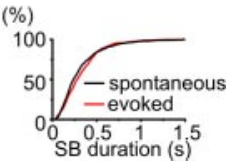

FIG. 3. Spindle-bursts evoked by whisker pad stimulation. A: electrical stimulation of the contralateral whisker pad (arrow) evokes a sensory potential followed by spindle-burst in the superfused P4 rat barrel cortex. Below, corresponding MUA (filtered at $>200 \mathrm{~Hz}$ ) and time-frequency analysis. $B$ : probability of sensory-evoked spindle-bursts in the superfused (chamber) and intact barrel cortex. $C$ : normalized power spectrum. $D$ : duration of spontaneous and sensory-evoked spindle-bursts. Pooled data from 14 P2-P7 rats, 583 stimulations, and 499 spindle-bursts.

after the EPSC ( $n=5$ cells; $P<0.05$ ). These results suggest that sensory stimulation evokes in cortical neurons AMPA/ kainate receptor-mediated EPSCs, probably of thalamocortical origin, and activates local interneurons that generate delayed barrage of GABA-PSCs. Sensory potentials were followed by spindle-bursts in eight of ten stimuli both in the superfused and intact barrel cortex (Fig. 3, $A$ and $B ; n=17$ rats). Powerspectrum (Fig. 3C) and spindle-burst duration analysis (Fig. $3 D$ ) did not reveal any difference between the stimulationevoked and spontaneous spindle-bursts in the superfused barrel cortex. Thus the physiological patterns of spindle-bursts and sensory-evoked cortical responses are preserved in the superfused barrel cortex preparation.

We further explored the pharmacological profile of spontaneous and sensory evoked activity in the superfused barrel cortex. Tetrodotoxin (TTX, $2 \mu \mathrm{M}$ ), a blocker of the voltagegated sodium channels, completely and reversibly suppressed spontaneous spindle-bursts (Fig. 4, $A$ and $E$ ), sensory-evoked potentials, and sensory-evoked spindle-bursts (Fig. $5 D ; n=3$ rats). AMPA/kainate receptors antagonist CNQX $(20 \mu \mathrm{M})$ completely and reversibly eliminated spontaneous spindlebursts (Fig. 4, $A$ and $E$ ), reduced sensory field potentials evoked by contralateral whisker pad stimulation to $8.8 \pm 0.3 \%$ of control values (Fig. 5, $A$ and $B$ ), and blocked sensoryevoked spindle-bursts, which was also evidenced by a reduction in the power of activity at the dominant frequency of the evoked spindle-burst oscillations $(18 \pm 2 \mathrm{~Hz})$ from $49.4 \pm$
A

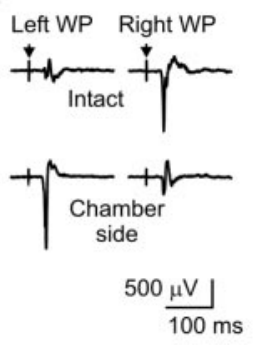

B

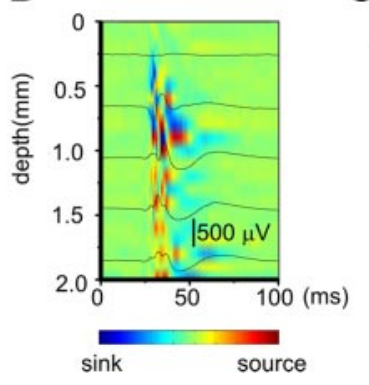

C

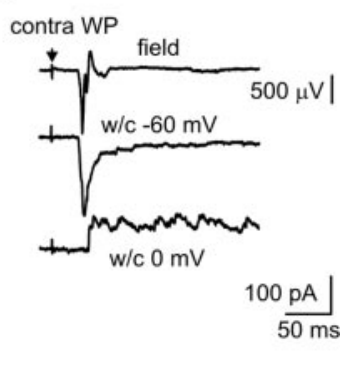

FIG. 2. Sensory potentials evoked by electrical whisker pad stimulation. A: sensory potentials evoked by the left ant right whisker pad (WP) stimulation in the intact left and superfused right barrel cortex. $B$ : depth profile of the sensory-evoked potentials in the superfused barrel cortex. $C$ : sensory-evoked response in barrel cortex recorded using field potential (depth, $400 \mu \mathrm{m}$ ) and whole cell patch-clamp (depth, $600 \mu \mathrm{m})$ recordings with low-chloride solution to discriminate between the glutamatergic $(-60 \mathrm{mV})$ and GABAergic $(0 \mathrm{mV})$ postsynaptic currents. 
16.4 to $0.15 \pm 0.03 \mu \mathrm{V}^{2}$ in the time frame of $300-1,000 \mathrm{~ms}$ after sensory stimulation (Fig. 5, $A$ and $D ; n=10$ rats; P2-P7). Spindle-bursts and sensory-evoked responses fully recovered 25-40 min after washout of CNQX (Fig. 5B). The amplitude of sensory responses in the intact barrel cortex was not affected by the CNQX applied to the superfused barrel cortex (Fig. 5B). Consistent with the extracellular data, whole cell recordings revealed complete suppression of the EPSCs and spindle-bursts (Fig. 5C; $n=3$ cells; depth $450-600 \mu \mathrm{m}$ ). Although spindleburst oscillations were virtually completely suppressed by CNQX, bursts of multiple units were still efficiently evoked by sensory stimulation and occurred spontaneously (Fig. 5A). This residual activity persisted in the presence of a high concentration of bath-applied CNQX $(50 \mu \mathrm{M} ; n=9)$ and after ipsilateral intraventricular CNQX injection $(1 \mu \mathrm{l}$ of $10 \mathrm{mM}$ CNQX, $n=$ 4). The mechanism underlying this residual activity at present remains unknown. The NMDA receptor antagonist D-APV (80 $\mu \mathrm{M})$ did not significantly affect sensory potentials and only

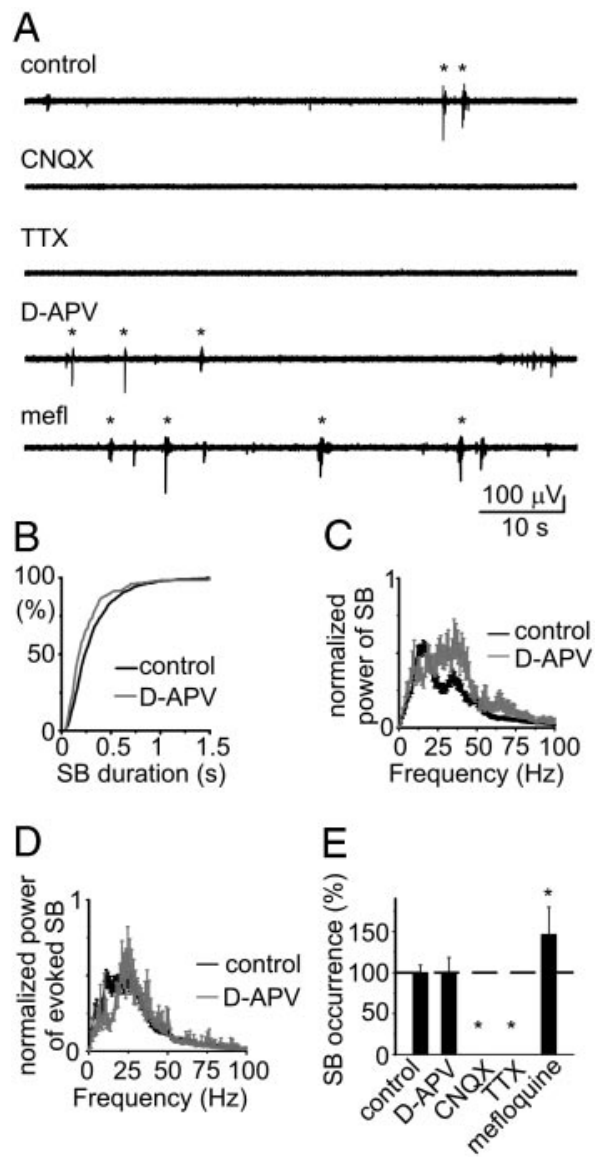

FIG. 4. Effect of the glutamate ionotropic receptors antagonists and tetrodotoxin (TTX) on spontaneous spindle-bursts. A: field potential recordings in control conditions and in the presence of the $\alpha$-amino-3-hydroxy-5-methyl-4isoxazolepropionic acid (AMPA)/kainate receptor antagonist 6-cyano-7-nitroquinoxaline-2,3-dione (CNQX, $20 \mu \mathrm{M})$, sodium channel blocker TTX $(2 \mu \mathrm{M})$, $N$-methyl-D-aspartate (NMDA) receptor antagonist D-2-amino-5-phosphonovaleric acid (D-APV) $(80 \mu \mathrm{M})$, and gap-junction blocker mefloquine $(50 \mu \mathrm{M})$. Recordings from P4 (control, CNQX, TTX, D-APV) and P2 (mefloquine) superfused barrel cortex. $B-D$ : effect of D-APV on the duration $(B)$ and normalized power of spontaneous $(C)$ and sensory-evoked $(D)$ spindle-bursts. Pooled data from 9 P3-P6 rats and 225 spontaneous and 214 evoked spindlebursts. $E$ : summary plot on the effect of D-APV ( $n=9$ rats; P3-P6), TTX ( $n=$ 3 rats; $\mathrm{P} 4-\mathrm{P} 6)$, CNQX ( $n=12$ rats; $\mathrm{P} 2-\mathrm{P} 7)$, and mefloquine $(n=5$ rats; $\mathrm{P} 1-\mathrm{P} 3)$ on the occurrence of spontaneous spindle-bursts.
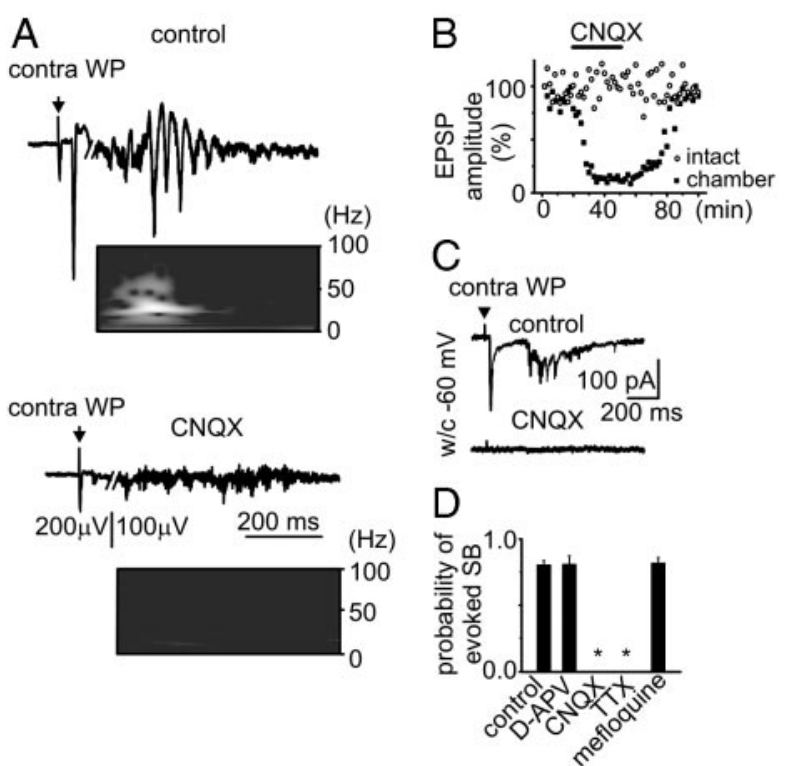

FIG. 5. Effect of AMPA/kainate receptor antagonist CNQX on the sensoryevoked spindle-bursts. $A$ : sensory-evoked potentials and spindle-bursts in control conditions (top) and in the presence of CNQX $(20 \mu \mathrm{M})$ (bottom). B: time course of the effect of CNQX on the amplitude of the sensory-evoked potentials in the superfused (squares) and intact barrel cortex (circles). $C$ : whole cell recordings of the sensory-evoked responses in control conditions and in the presence of CNQX $(20 \mu \mathrm{M}) . D$ : summary plot on the effect of D-APV ( $n=5$ rats; P3-P6), TTX $(n=3$ rats; P4-P6), CNQX ( $n=7$ rats; $\mathrm{P} 2-\mathrm{P} 7)$, and mefloquine $(n=5$ rats; $\mathrm{P} 1-\mathrm{P} 3)$ on the probability of sensoryevoked spindle-bursts $(* P<0.05)$.

modestly affected spindle-bursts. The occurrence of spontaneous spindle-bursts $\left(5.1 \pm 0.8 \mathrm{~min}^{-1} ; n=9\right)$ and the probability of evoking a spindle-burst $(0.8 \pm 0.1 ; n=5)$ was not significantly modified by D-APV; however, the duration of spindle-bursts was slightly shortened (from $292 \pm 14$ to $264 \pm$ $19 \mathrm{~ms})$, reduced in power $\left(33 \pm 14\right.$ to $\left.8 \pm 3 \mu \mathrm{V}^{2}\right)$, and the oscillation frequency was slightly increased (Figs. $4, B-E$ and $5 D ; n=9$ rats; P2-P7). Taken together, these results suggest that generation of spindle-burst oscillation is based on glutamatergic synapses with the major contribution of AMPA/ kainate receptors and slight participation of NMDA receptors.

In the next series of experiments we studied the contribution of GABAergic synapses to the generation of spindle-bursts by applying the $\mathrm{GABA}_{\mathrm{A}}$-receptor antagonist gabazine. To control the efficacy of gabazine in the superfused cortex, we studied its action on the $\mathrm{GABA}_{\mathrm{A}}-\mathrm{PSC}$ recorded with low-chloride solution at $0 \mathrm{mV}$ holding potential. Gabazine $(40 \mu \mathrm{M})$ completely blocked spontaneous and sensory-evoked GABA $\mathrm{A}_{\mathrm{A}}-\mathrm{PSCs}(n=$ 5 neurons; depth 450-600 $\mu \mathrm{m}$; Fig. 6B). Gabazine did not significantly change the amplitude of the early negative peak of the sensory-evoked field potentials [control: $450 \pm 69 \mu \mathrm{V}$, gabazine: $496 \pm 78 \mu \mathrm{V}(110 \pm 6 \%) ; n=5 ; P>0.05$; P3-P5; Fig. $6 B$ ]. This is in keeping with the fact that the early part of the sensory-evoked potential is purely glutamatergic thalamocortical EPSP and the GABAergic conductance is delayed (Figs. $2 C$ and $6 B$,*; see also above and Agmon and O'Dowd 1992; Agmon et al. 1996; Moore and Nelson 1998). However, gabazine induced the appearance or strongly enhanced (to $929 \pm 6 \% ; n=5$ ) the late negative peak of the sensory EPSP, which probably reflects the intracortical spread of excitation (Fig. $6 B, * *$ ). Blockade of $\mathrm{GABA}_{\mathrm{A}}$ receptors by gabazine also 

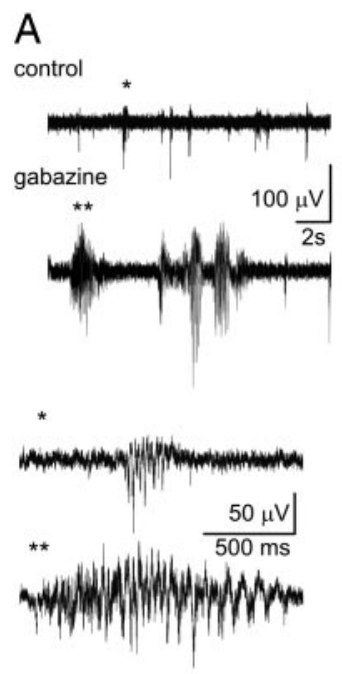

B
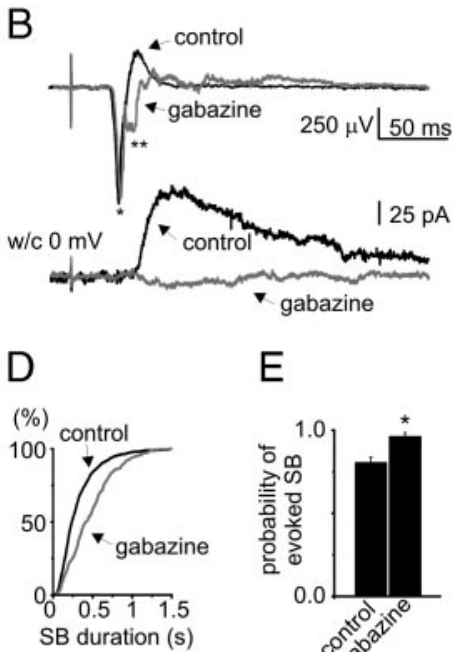

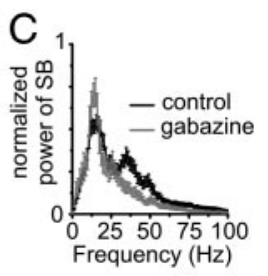

$\mathrm{F}$

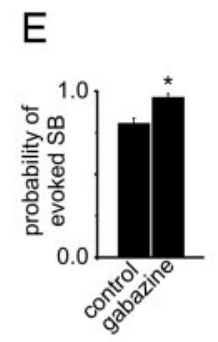

FIG. 6. Effect of the $\mathrm{GABA}_{\mathrm{A}}$-receptor-acting drugs on spindle-bursts. A: field potential recordings from superfused barrel cortex in control conditions and in the presence of the $\mathrm{GABA}_{\mathrm{A}}$ receptor antagonist gabazine $(20 \mu \mathrm{M})$. Events marked by asterisks are shown below on expanded timescale. $B$ : sensory-evoked response in barrel cortex recorded using field potential (depth, $400 \mu \mathrm{m})\left(^{*}\right.$, early; **, late negative peak of the sensory evoked field potential) and whole cell patch-clamp (depth, $600 \mu \mathrm{m}$ ) recordings with low-chloride pipette solution in control and in the presence of $\mathrm{GABA}_{\mathrm{A}}$ antagonist at $0 \mathrm{mV}$ membrane potential. $C-F$ : effect of gabazine on the normalized power spectrum $(C)$, duration of spontaneous spindle-bursts $(D)$, and the probability of the evoked spindle-bursts $(E) . F$ : summary plot on the occurrence of spontaneous spindle-bursts in the presence of the $\mathrm{GABA}_{\mathrm{A}}$-acting drugs: antagonist gabazine (40 $\mu \mathrm{M})$, NKCC1 antagonist bumetanide $(40 \mu \mathrm{M})$, and diazepam $(70 \mu \mathrm{M})(* P<0.05)$. significantly increased spontaneous cortical activity by almost doubling the occurrence of spontaneous spindle-bursts, as well as increasing the probability of evoking a spindle-burst by stimulation to $0.96 \pm 0.02(n=10 ; P<0.05$; Fig. $6, A, E$, and $F)$. The dominant frequency of spindle-burst oscillations was not significantly modified by gabazine (Fig. 6C), althought the power increased from $16 \pm 5$ to $24 \pm 6 \mu \mathrm{V}^{2}$ for spontaneous and from $9 \pm 2$ to $22 \pm 5 \mu \mathrm{V}^{2}$ for sensory-evoked spindles, and the duration of spindle-bursts increased from $323 \pm 13$ to $658 \pm 41 \mathrm{~ms}(n=10$; P2-P6; $P<0.01$, Fig. $6 D)$. Superfusion with the NKCC1 antagonist bumetanide $(20 \mu \mathrm{M})$, which negatively shifts the $\mathrm{GABA}_{\mathrm{A}}$ reversal potential in neonatal cortical neurons (Yamada et al. 2004), did not appreciably affect the occurrence and the power-frequency characteristics of spindlebursts $(n=6$; Fig. $6 F$ ). Consistent with these results, systemic intraperitoneal injection of bumetanide $(0.6 \mathrm{~g} / \mathrm{kg})$ did not affect spindle-bursts ( $n=3$; data not shown). Application of the positive allosteric $\mathrm{GABA}_{\mathrm{A}}$ modulator diazepam $(70 \mu \mathrm{M})$, which transiently increases the frequency of the hippocampal GDPs in vitro (Khalilov et al. 1999), reduced the frequency of spindle-burst occurrence by twofold without any effect on the frequency of spindle-burst oscillations and their power (Fig. $6 F ; n=5$; P2-P6). These results suggest that GABAergic transmission is not necessarily required for pacing the rhythm of spindle-burst oscillations but that it plays an inhibitory role at the network level.

Horizontal compartmentalization is a salient feature of spindle-burst (Khazipov et al. 2004b). Therefore in the next experiment we tested a hypothesis that GABAergic synapses are involved in compartmentalization of spindle-bursts. Using four site recordings from the barrel cortex with a separation distance between the electrodes of $500 \mu \mathrm{m}$, we found that spindlebursts are predominantly local events with a relatively low coefficient of cross-correlation of activity between the recording sites (Fig. 7A; $n=5$; P2-P7) in keeping with the results obtained in the body representation areas of somatosensory cortex (Khazipov et al. 2004b). In the presence of gabazine (40 $\mu \mathrm{M})$, spindle-bursts were synchronously recorded from several (and often all four) recording sites, accompanied with a strong increase in the cross-correlation between recording sites (Fig. $7 B)$. To verify whether surface application of gabazine does not abolish the potential deep burst generators we administered gabazine intraperitoneally $(0.3 \mathrm{mg} / \mathrm{kg})$ and found a similar increase in the occurrence of spindle-bursts and their crosscorrelation over large cortical areas $(n=6$; data not shown). Thus although $\mathrm{GABA}_{\mathrm{A}}$ receptors are not instrumental for pacing the rhythm of spindle-bursts, they appear to play a critical role in the compartmentalization of spindle-burst activity - probably by the mechanism of surround inhibition.

Several studies using intact cortex and cortical slices in vitro indicated an important role for gap junctions in the generation of correlated neuronal activity during the early postnatal period (Dupont et al. 2006; Kandler and Katz 1995, 1998a,b; Peinado 2000, 2001; Yuste et al. 1992, 1995). Therefore we studied the effect of the gap-junction blocker mefloquine $(50 \mu \mathrm{M})$ (Cruikshank et al. 2004) on spindle-bursts. Mefloquine increased the occurrence of spontaneous spindle-bursts to $146 \pm 33 \%(n=$ 7; P1-P3; $P<0.05)$ without affecting the power and frequency of the spindle-burst oscillations (Fig. $4 E$ ) and probability of evoked spindle-bursts (Fig. 5D). An increase in the occurrence of spontaneous spindle-bursts to $157 \pm 14 \%$ was also observed after injection of mefloquine $(25 \mathrm{mM}, 100 \mathrm{nl})$ into the cortex (depth $1,000 \mu \mathrm{m} ; n=4$ rats; P2-P3; $P<0.05$ ). These results suggest that spindle-bursts significantly differ in their generation mechanisms from the early patterns of cortical activity in vitro that are blocked by the gap-junction antagonists (Dupont et al. 2006; Kandler and Katz 1995, 1998a,b; Peinado 2000, 2001; Yuste et al. 1992, 1995).

\section{I S C U S S I ON}

The principal findings of the present study can be summarized as follows: 1) spindle-bursts are the principal pattern of activity in the barrel cortex during the first week of postnatal life; like spindle-bursts in the body representation areas, spindle-bursts in the barrel cortex can be evoked by sensory stimulation; 2) the principal properties of spindle-bursts are preserved in the superfused cortex preparation that enables easy pharmacological manipulations and recordings; 3) generation of spindle-burst oscillations requires AMPA/kainate receptor activity at glutamatergic synapses; NMDA receptors and gap junctions are slightly involved in the generation of spindle-bursts; and 4) GABAergic synapses importantly con- 
A

control

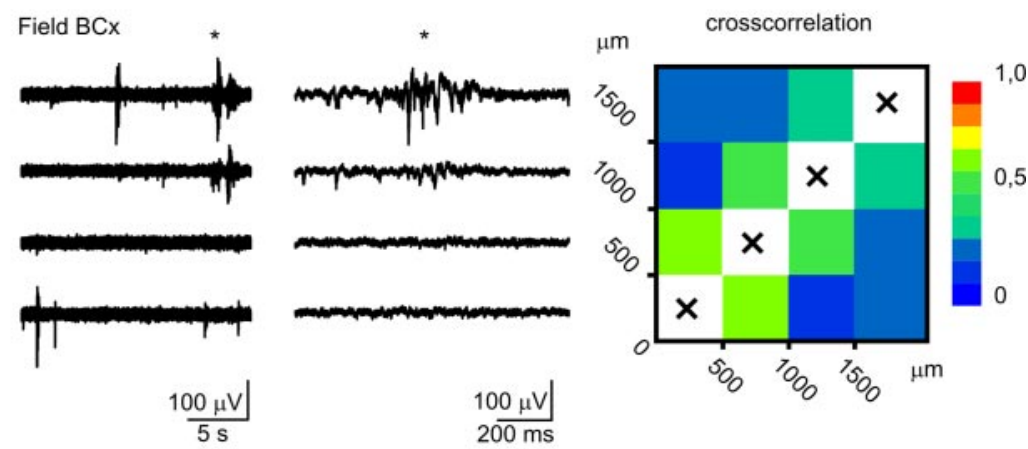

B

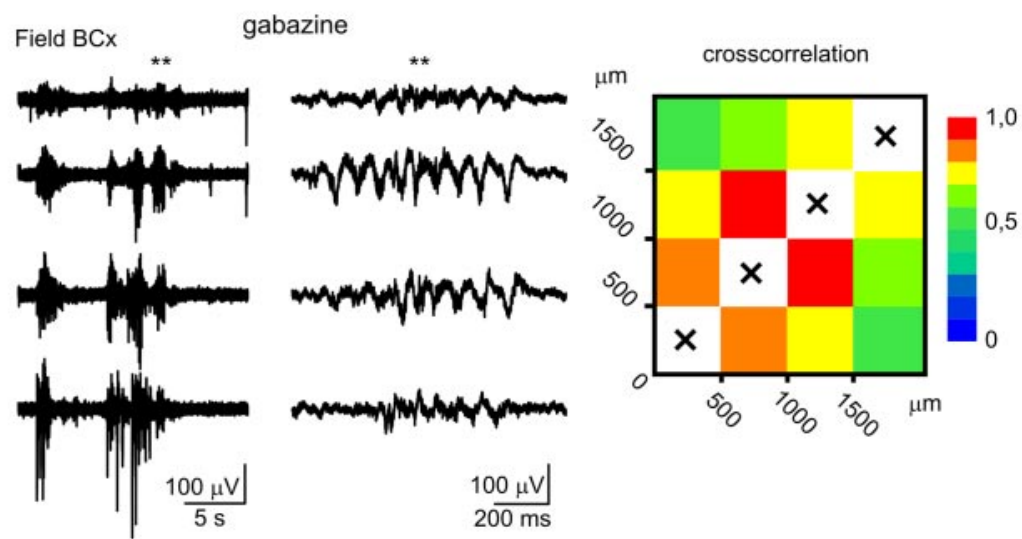

FIG. 7. Effect of the $\mathrm{GABA}_{\mathrm{A}}$ antagonist gabazine on the compartmentalization of spindle-bursts. $A$ : field-potential recordings from the superfused barrel cortex with a 4-microelectrode array $(500-\mu \mathrm{m}$ separation distance between the electrodes) in control conditions and $(B)$ in the presence of gabazine $(40 \mu \mathrm{M})$. Spindle-burst marked by black asterisk on $A$ (left) is shown on an expanded timescale in the middle. On the right, cross-correlation analysis of spindle-bursts at 4 recordings sites (pooled data from 6 rats).

tribute to the compartmentalization of spindle-bursts by surround inhibition.

We used the novel methodological approach of superfused neocortex in vivo to provide a stable platform for electrophysiological recordings and pharmacological manipulation. Advantages of the present technique compared with conventional in vivo recordings can be summarized as follows: 1) the cortex is exposed and the recording electrodes can be placed under visual control as easily as in the intact cortex or cortical slices in vitro and 2) rapid pharmacological manipulations, including application and washout of drugs, are possible. This is a distinct advantage over other in vivo techniques that require systemic or local injections. An important finding of the present study is that the physiological pattern of spindle-bursts is preserved in the superfused neocortex in vivo. The reason for the higher frequency of occurrence of spindle-bursts in the superfused cortex is unknown, but it may be attributable to the washing out of urethane from the superfused cortex and/or some difference in the composition of ACSF from that of the physiological cerebrospinal fluid. Other than the higher occurrence, the characteristics of spindle-bursts and sensory-evoked activity in the superfused barrel cortex were not significantly different from the intact barrel cortex. Thus the preparation of the superfused neocortex combines the in vitro approaches with the in vivo situation, thus enabling one to study the physiological patterns of activity that appear to be much more complex in the intact brain than in isolated slices (Steriade 2001).

Our results suggest that the generation of spindle-bursts in the neonatal barrel cortex is primarily based on synapses between glutamatergic cells, with the major contribution of the AMPA/kainate receptors. Because the glutamatergic synapses on cortical neurons are mainly provided by the intracortical connections and thalamocortical input, at least two models of spindle-burst oscillations can be proposed: intracortical and thalamocortical. In the intracortical model, the spindle-burst is a local oscillation generated in the network of interconnected cortical glutamatergic neurons. Each cycle of oscillation is set by synchronous activation of local population by mutual excitation of cortical neurons by AMPA/kainate receptors at the cortico-cortical synapses. Because the $\mathrm{GABA}_{\mathrm{A}}$ antagonists did not significantly affect the frequency of spindle-burst oscillations, neuronal inhibition probably comes from an afterhyperpolarization mediated by the voltage- and calcium-dependent potassium channels. In the thalamocortical model, spindlebursts are generated by a rhythmic thalamocortical input provided by oscillation in thalamic neurons, similar to the mechanism of adult sleep spindles (Steriade et al. 1993). The spatial confinement of spindle-bursts in the latter model could be explained by the relative sparsity of long-range intracortical and corticothalamic connections, which are important for synchronization of sleep spindles over the entire cortex (Contreras et al. 1996). This is aided by efficient shunting surround inhibition of depolarizing GABA. The two models are not incompatible and both thalamic and cortical oscillators may resonate given that their intrinsic frequencies are close.

In both the present and previous studies whole cell recordings revealed GABAergic synaptic currents phase-locked with the local field potential oscillations (Hanganu et al. 2006; Khazipov et al. 2004b), suggesting that interneurons are activated during spindle-bursts. However, because blockade of $\mathrm{GABA}_{\mathrm{A}}$ receptors did not significantly affect the frequency of oscillation it seems that GABAergic interneurons play only a minor role in pacing of the rhythm of oscillation. This differs 
from the adult brain in which the major patterns of activity are significantly influenced by interneurons (Freund and Buzsáki 1996; Fuentealba and Steriade 2005). GABAergic inhibition undergoes significant developmental changes during the first postnatal week, during which time GABA - acting by $\mathrm{GABA}_{\mathrm{A}}$ receptors-depolarizes immature neocortical neurons because of elevated intracellular $\left[\mathrm{Cl}^{-}\right]_{\mathrm{i}}$ (LoTurco et al. 1995; Luhmann and Prince 1991; Owens et al. 1996; Yamada et al. 2004; Yuste and Katz 1991). Interestingly, in the hippocampus, GDPs in vitro and sharp waves in vivo are blocked by the NKCC1 antagonist bumetanide, which shifts the reversal potential of the $\mathrm{GABA}_{\mathrm{A}}$-mediated responses toward negative values (Dzhala et al. 2005; Sipilä et al. 2006). Although a similar effect of bumetanide on the $\mathrm{GABA}_{\mathrm{A}}$ reversal potential was found in the neocortical neonatal neurons (Yamada et al. 2004), we did not observe any effect of bumetanide on spindlebursts. Therefore it appears that early hippocampal patterns of sharp waves and GDPs are more dependent on the depolarizing/excitatory GABA than the neocortical pattern of spindleburst, which is consistent with the observations made in vitro (Garaschuk et al. 2000).

Although GABAergic interneurons are not directly involved in setting the rhythm of spindle-burst oscillations, they play important role in their horizontal compartmentalization. Blockade of $\mathrm{GABA}_{\mathrm{A}}$ receptors significantly increased the area of activation during spindle-bursts, evidenced by increases in the amplitude and power of oscillations, duration of spindle-bursts, and their horizontal spread. Thus compartmentalization of spindle-bursts is determined not only by the vertical segregation of the sensory feedback-driven essentially AMPA/kainitereceptor-mediated somatotopic excitation (Agmon et al. 1996; Bureau et al. 2004; Ferezou et al. 2006; Higashi et al. 2002; Khazipov et al. 2004b; Kidd and Isaac 1999; Petersen and Sakmann 2001) but also by surround GABAergic inhibition, which prevents the horizontal spread of activity by long-range glutamatergic cortical connections, a pattern observed in the adult neocortex (Chagnac-Amitai and Connors 1989; Fox et al. 2003; Sun et al. 2006). The inhibitory action of GABA at the network level is probably explained by the shunting mechanisms amplified by the activation of the voltage-gated potassium channels and inactivation of sodium channels (BorgGraham et al. 1998; Gao et al. 1998; Gulledge and Stuart 2003; $\mathrm{Lu}$ and Trussell 2001). These results are in general agreement with the findings that administration of $\mathrm{GABA}_{\mathrm{A}}$ antagonists induces hypersynchronous seizurelike activity in the neocortex in vivo by P3 (Baram and Snead 1990) and in vitro by P2 (Wells et al. 2000).

Comparing various neonatal patterns and mechanisms of neuronal synchronization described in vitro and in the present study in vivo, it appears that the in vivo and in vitro patterns share some common features, although none of the patterns described in vitro fully matches spindle-bursts, probably because the in vitro models cannot fully reproduce the in vivo conditions (Steriade 2001). Studies using cortical preparations in vitro emphasized the role of several developmentally regulated mechanisms of neuronal synchronization in the developing cortex, including 1) gap junctions (Dupont et al. 2006; Kandler and Katz 1995, 1998a,b; Peinado 2000, 2001; Yuste et al. 1992, 1995), 2) NMDA receptors (Ben-Ari et al. 1989; Dupont et al. 2006; Leinekugel et al. 1997), and 3) depolarizing GABA (Ben-Ari et al. 1989; Garaschuk et al. 1998, 2000;
Khazipov et al. 1997, 2004a ; Leinekugel et al. 1997; Sipilä et al. 2005, 2006). Our results suggest that the generation of the in vivo neocortical pattern of spindle-bursts relies on a rather "mature" mechanism based on AMPA/kainite-receptor-mediated synaptic transmission. It should be noted that AMPA/ kainate antagonists were also efficient in suppressing some types of cortical network activity in the neonatal period, including spontaneous-but not stimulation-evoked-GDPs (Ben-Ari et al. 1989; Bolea et al. 1999; Khazipov et al. 1997; Lamsa et al. 2000), polysynaptic events in barrel cortex evoked by thalamic stimulation (Agmon et al. 1996), and neocortical early network oscillations (Garaschuk et al. 2000).

In the rodent somatosensory cortex, activity-dependent cortical plasticity is maximal over an early "critical" postnatal developmental period, which is characterized by enhanced synaptic plasticity and by the potential for profound alterations of anatomical and functional organization of the barrel cortex by manipulation of the sensory input (Crair and Malenka 1995; Erzurumlu and Kind 2001; Feldman et al. 1998, 1999; Fox 2002; Fox and Wong 2005; Katz and Crowley 2002; Katz and Shatz 1996; Van der Loos and Woolsey 1973). Glutamate receptor blockade during the first postnatal week was previously shown to disrupt the topographic refinement of thalamocortical connectivity and columnar organization of the barrel cortex (Elias et al. 2003; Fox et al. 1996) and impairs formation of the intracortical connectivity (Dagnew et al. 2003). We propose that local spindle-burst oscillations, driven by glutamatergic synapses and compartmentalized by GABAergic synapses, contribute to development of the barrel cortex during the critical period of developmental plasticity.

\section{A C K N OW LED G MEN T S}

We thank G. Buzsáki, A. Sirota, M. Colonnese, M. Milh, R. Tyzio, I. Hanganu, and A. Zakharov for helpful comments on the manuscript.

\section{G R A N T S}

This work was supported by grants from the North Atlantic Treaty Organization and Université Méditerrenéen to M. Minlebaev, Institut National de la Santé et de la Recherche Médicale to Y. Ben-Ari, and Fondation pour la Recherche Médicale and Agence National de la Recherche to R. Khazipov.

\section{REFERENCES}

Agmon A, Hollrigel G, O'Dowd DK. Functional GABAergic synaptic connection in neonatal mouse barrel cortex. J Neurosci 16: 4684-4695, 1996. Agmon A, O'Dowd DK. NMDA receptor-mediated currents are prominent in the thalamocortical synaptic response before maturation of inhibition. J Neurophysiol 68: 345-349, 1992.

Baram TZ, Snead OC. Bicuculline induced seizures in infant rats: ontogeny of behavioral and electrocortical phenomena. Dev Brain Res 57: 291-295, 1990.

Ben-Ari Y. Developing networks play a similar melody. Trends Neurosci 24: 353-360, 2001.

Ben-Ari Y, Cherubini E, Corradetti R, Gaïarsa J-L. Giant synaptic potentials in immature rat CA3 hippocampal neurones. J Physiol 416: 303-325, 1989.

Bolea S, Avignone E, Berretta N, Sanchez-Andres JV, Cherubini E. Glutamate controls the induction of GABA-mediated giant depolarizing potentials through AMPA receptors in neonatal rat hippocampal slices. J Neurophysiol 81: 2095-2102, 1999.

Borg-Graham LJ, Monier C, Fregnac Y. Visual input evokes transient and strong shunting inhibition in visual cortical neurons. Nature 393: 369-373, 1998.

Buhl DL, Buzsáki G. Developmental emergence of hippocampal fast-field "ripple" oscillations in the behaving rat pups. Neuroscience 134: 14231430, 2005.

Bureau I, Shepherd GM, Svoboda K. Precise development of functional and anatomical columns in the neocortex. Neuron 42: 789-801, 2004. 
Chagnac-Amitai Y, Connors BW. Horizontal spread of synchronized activity in neocortex and its control by GABA-mediated inhibition. J Neurophysiol 61: 747-758, 1989.

Contreras D, Destexhe A, Sejnowski TJ, Steriade M. Control of spatiotemporal coherence of a thalamic oscillation by corticothalamic feedback. Science 274: 771-774, 1996.

Crair MC, Malenka RC. A critical period for long-term potentiation at thalamocortical synapses. Nature 375: 325-328, 1995.

Cruikshank SJ, Hopperstadt M, Younger M, Connors BW, Spray DC, Srinivas M. Potent block of Cx36 and Cx50 gap junction channels by mefloquine. Proc Natl Acad Sci USA 101: 12364-12369, 2004.

Dagnew E, Latchamsetty K, Erinjeri JP, Miller B, Fox K, Woolsey TA. Glutamate receptor blockade alters the development of intracortical connections in rat barrel cortex. Somatosens Mot Res 20: 77-84, 2003.

Dupont E, Hanganu IL, Kilb W, Hirsch S, Luhmann HJ. Rapid developmental switch in the mechanisms driving early cortical columnar networks. Nature 439: 79-83, 2006.

Dzhala VI, Talos DM, Sdrulla DA, Brumback AC, Mathews GC, Benke TA, Delpire E, Jensen FE, Staley KJ. NKCC1 transporter facilitates seizures in the developing brain. Nat Med 11: 1205-1213, 2005

Elias DY, Latchamsetty K, Erinjeri JP, Miller B, Fox K, Woolsey TA. Glutamate receptor blockade alters the development of intracortical connections in rat barrel cortex. Somatosens Mot Res 20: 77-84, 2003.

Erzurumlu RS, Kind PC. Neural activity: sculptor of "barrels" in the neocortex. Trends Neurosci 24: 589-595, 2001

Feldman DE, Nicoll RA, Malenka RC. Synaptic plasticity at thalamocortical synapses in developing rat somatosensory cortex: LTP, LTD, and silent synapses. J Neurobiol 41: 92-101, 1999.

Feldman DE, Nicoll RA, Malenka RC, Isaac JT. Long-term depression at thalamocortical synapses in developing rat somatosensory cortex. Neuron 21: 347-357, 1998 .

Ferezou I, Bolea S, Petersen CCH. Visualizing the cortical representation of whisker touch: voltage-sensitive dye imaging in freely moving mice. Neuron 50: 617-629, 2006

Fox K. Anatomical pathways and molecular mechanisms for plasticity in the barrel cortex. Neuroscience 111: 799-814, 2002

Fox K, Schlaggar BL, Glazewski S, O'Leary DD. Glutamate receptor blockade at cortical synapses disrupts development of thalamocortical and columnar organization in somatosensory cortex. Proc Natl Acad Sci USA 93: 5584-5589, 1996

Fox K, Wong ROL. A comparison of experience-dependent plasticity in the visual and somatosensory systems. Neuron 48: 465-477, 2005.

Fox K, Wright N, Wallace H, Glazewski S. The origin of cortical surround receptive fields studied in the barrel cortex. J Neurosci 23: 8380-8391, 2003.

Freund T, Buzsáki G. Interneurons of the hippocampus. Hippocampus 6: 345-470, 1996

Fuentealba P, Steriade M. The reticular nucleus revisited: intrinsic and network properties of a thalamic pacemaker. Prog Neurobiol 75: 125-141, 2005.

Gao XB, Chen G, van den Pol AN. GABA-dependent firing of glutamateevoked action potentials at AMPA/kainate receptors in developing hypothalamic neurons. J Neurophysiol 79: 716-726, 1998.

Garaschuk O, Hanse E, Konnerth A. Developmental profile and synaptic origin of early network oscillations in the CA1 region of rat neonatal hippocampus. J Physiol 507: 219-236, 1998.

Garaschuk O, Linn J, Eilers J, Konnerth A. Large-scale oscillatory calcium waves in the immature cortex. Nat Neurosci 3: 452-459, 2000.

Gulledge AT, Stuart GJ. Excitatory actions of GABA in the cortex. Neuron 37: 299-309, 2003.

Hanganu IL, Ben-Ari Y, Khazipov R. Retinal waves trigger spindle bursts in the neonatal rat visual cortex. J Neurosci 26: 6728-6736, 2006.

Higashi S, Molnar Z, Kurotani T, Toyama K. Prenatal development of neural excitation in rat thalamocortical projections studied by optical recording. Neuroscience 115: 1231-1246, 2002

Kandler K, Katz LC. Neuronal coupling and uncoupling in the developing nervous system. Curr Opin Neurobiol 5: 98-105, 1995.

Kandler K, Katz LC. Coordination of neuronal activity in developing visual cortex by gap junction-mediated biochemical communication. J Neurosci 18: 1419-1427, 1998a.

Kandler K, Katz LC. Relationship between dye coupling and spontaneous activity in developing ferret visual cortex. Dev Neurosci 20: 59-64, 1998b.

Katz LC, Crowley JC. Development of cortical circuits: lessons from ocular dominance columns. Nat Rev Neurosci 3: 34-42, 2002.
Katz LC, Shatz CJ. Synaptic activity and the construction of cortical circuits. Science 274: 1133-1138, 1996.

Khalilov I, Dzhala V, Ben-Ari Y, Khazipov R. Dual role of GABA in the neonatal rat hippocampus. Dev Neurosci 21: 310-319, 1999.

Khazipov R, Holmes GL. Synchronization of kainate-induced epileptic activity via GABAergic inhibition in the superfused rat hippocampus in vivo. J Neurosci 23: 5337-5341, 2003.

Khazipov R, Khalilov I, Tyzio R, Morozova E, Ben-Ari Y, Holmes GL. Developmental changes in GABAergic actions and seizure susceptibility in the rat hippocampus. Eur J Neurosci 19: 590-600, 2004a.

Khazipov R, Leinekugel X, Khalilov I, Gaïarsa J-L, Ben-Ari Y. Synchronization of GABAergic interneuronal network in CA3 subfield of neonatal rat hippocampal slices. J Physiol 498: 763-772, 1997.

Khazipov R, Luhmann HJ. Early patterns of electrical activity in the developing cerebral cortex of humans and rodents. Trends Neurosci 29: 414-418, 2006.

Khazipov R, Sirota A, Leinekugel X, Holmes GL, Ben-Ari Y, Buzsáki G. Early motor activity drives spindle bursts in the developing somatosensory cortex. Nature 432: 758-761, 2004b.

Kidd FL, Isaac JT. Developmental and activity-dependent regulation of kainate receptors at thalamocortical synapses. Nature 400: 569-573, 1999.

Lamsa K, Palva JM, Ruusuvuori E, Kaila K, Taira T. Synaptic GABA(A) activation inhibits AMPA-kainate receptor-mediated bursting in the newborn (P0-P2) rat hippocampus. J Neurophysiol 83: 359-366, 2000.

Leinekugel X, Khalilov I, Ben-Ari Y, Khazipov R. Giant depolarizing potentials: the septal pole of the hippocampus paces the activity of the developing intact septohippocampal complex in vitro. J Neurosci 18: 63496357, 1998.

Leinekugel X, Khazipov R, Cannon R, Hirase H, Ben-Ari Y, Buzsáki G. Correlated bursts of activity in the neonatal hippocampus in vivo. Science 296: 2049-2052, 2002.

Leinekugel X, Medina I, Khalilov I, Ben-Ari Y, Khazipov R. $\mathrm{Ca}^{2+}$ oscillations mediated by the synergistic excitatory actions of $\mathrm{GABA}_{\mathrm{A}}$ and NMDA receptors in the neonatal hippocampus. Neuron 18: 243-255, 1997.

LoTurco JJ, Owens DF, Heath MJ, Davis MB, Kriegstein AR. GABA and glutamate depolarize cortical progenitor cells and inhibit DNA synthesis. Neuron 15: 1287-1298, 1995.

Lu T, Trussell LO. Mixed excitatory and inhibitory GABA-mediated transmission in chick cochlear nucleus. J Physiol 535: 125-131, 2001.

Luhmann HJ, Prince DA. Postnatal maturation of the GABAergic system in rat neocortex. J Neurophysiol 247-263, 1991.

Margrie TW, Brecht M, Sakmann B. In vivo, low-resistance, whole-cell recordings from neurons in the anaesthetized and awake mammalian brain. Pfluegers Arch 444: 491-498, 2002.

Moody WJ, Bosma MM. Ion channel development, spontaneous activity, and activity-dependent development in nerve and muscle cells. Physiol Rev 85: 883-941, 2005.

Moore CI, Nelson SB. Spatio-temporal subthreshold receptive fields in the vibrissa representation of rat primary somatosensory cortex. J Neurophysiol 80: 2882-2892, 1998.

O'Donovan MJ. The origin of spontaneous activity in developing networks of the vertebrate nervous system. Curr Opin Neurobiol 9: 94-104, 1999.

Owens DF, Boyce LH, Davis MB, Kriegstein AR. Excitatory GABA responses in embryonic and neonatal cortical slices demonstrated by gramicidin perforated-patch recordings and calcium imaging. J Neurosci 16: 6414-6423, 1996

Peinado A. Traveling slow waves of neural activity: a novel form of network activity in developing neocortex. J Neurosci 20: RC54, 2000

Peinado A. Immature neocortical neurons exist as extensive syncitial networks linked by dendrodendritic electrical connections. J Neurophysiol 85: 620629, 2001.

Petersen CCH, Sakmann B. Functionally independent columns of rat somatosensory barrel cortex revealed with voltage-sensitive dye imaging. J Neurosci 21: 8435-8446, 2001.

Pihko E, Lauronen L. Somatosensory processing in healthy newborns. Exp Neurol 190, Suppl. 1: S2-S7, 2004.

Sipilä ST, Huttu K, Soltesz I, Voipio J, Kaila K. Depolarizing GABA acts on intrinsically bursting pyramidal neurons to drive giant depolarizing potentials in the immature hippocampus. J Neurosci 25: 5280-5289, 2005.

Sipilä ST, Schuchmann S, Voipio J, Yamada J, Kaila K. The cationchloride cotransporter (NKCC1) promotes sharp waves in the neonatal rat hippocampus. J Physiol 573: 765-773, 2006.

Steriade M. Impact of network activities on neuronal properties in corticothalamic systems. J Neurophysiol 86: 1-39, 2001. 
Steriade M, McCormick DA, Sejnowski TJ. Thalamocortical oscillations in the sleeping and aroused brain. Science 262: 679-685, 1993.

Sun QQ, Huguenard JR, Prince DA. Barrel cortex microcircuits: thalamocortical feedforward inhibition in spiny stellate cells is mediated by a small number of fast-spiking interneurons. J Neurosci 26: 1219-1230, 2006.

Van der Loos H, Woolsey TA. Somatosensory cortex: structural alterations following early injury to sense organs. Science 179: 395-398, 1973.

Wells JE, Porter JT, Agmon A. GABAergic inhibition suppresses paroxysmal network activity in the neonatal rodent hippocampus and neocortex. J Neurosci 20: 8822-8830, 2000.
Yamada J, Okabe A, Toyoda H, Kilb W, Luhmann HJ, Fukuda A. Cl-uptake promoting depolarizing GABA actions in immature rat neocortical neurones is mediated by NKCC1. J Physiol 557: 829-841, 2004.

Yuste R, Katz LC. Control of postsynaptic $\mathrm{Ca}^{2+}$ influx in developing neocortex by excitatory and inhibitory neurotransmitters. Neuron 6: 333344, 1991.

Yuste R, Nelson DA, Rubin WW, Katz LC. Neuronal domains in developing neocortex: mechanisms of coactivation. Neuron 14: 7-17, 1995.

Yuste R, Peinado A, Katz LC. Neuronal domains in developing neocortex. Science 257: 665-669, 1992. 